\title{
The time to save Africa's vultures is NOW!
}

\section{Munir Virani}

The Peregrine Fund

5688 West Flying Hawk Lane, Boise, Idaho 83709

PO Box 45111-00100 Nairobi, Kenya

virani.munir@peregrinefund.org

http://dx.doi.org/10.4314/vulnew.v73i1.7

Humanity's earliest musical roots go back nearly 40,000 years ago when a flute made out of bone was discovered in a cave in Germany. The bone belonged to a vulture! Since that time and probably even earlier, our ancestors have closely interacted with vultures to help dispose of their loved ones through sky burials, as religious insignias for ancient Egyptian and modern Hindu civilizations, and as symbols of eternal flying grace. Fast forward to 2017 and given the growth of our kind, one in five species of all wildlife populations is threatened with extinction. Vultures are without a doubt one of the most highly threatened groups of vertebrates on earth. There are several inherent ecological traits that likely contribute to vultures' extinction risk, including their large body masses, slow reproductive rates and highlyspecialised diets. The greatest external threat to vultures, however, is poisoning - lead in California Condors, pesticides in African and European vultures, and non-steroidal anti-inflammatories in Asian vultures.

Vultures play a vital role in Africa's savannah landscapes by rapidly consuming carcasses, which could otherwise spread pathogenic organisms via feral dogs and other mammalian scavengers. Loss of vultures results in a loss in effective nutrient cycling, causing ecosystem imbalance

Our planet has entered an era of mass extinction unparalleled since the dinosaurs died out 65 million years ago. There are 1227 species of birds (nearly $12 \%$ of all birds) threatened with extinction - 192 of these are critically endangered. According to a 2015 study coauthored by Paul Ehrlich and colleagues, this spectre of extinction 39 
hangs over about $41 \%$ of all amphibian species and $26 \%$ of all mammals, according to the International Union for Conservation of Nature (IUCN). Over this global disaster are the fingerprints of habitat loss, overexploitation, invasive organisms, pollution, poisoning and climate change. The study also highlighted that $56 \%$ of species in Africa have lost $80 \%$ of their
historical range.

Why does the loss of populations and biological diversity matter? Aside from being a prelude to species extinction, these losses rob us of crucial ecosystem services such as crop pollination by bees and other pollinators, pest control by insectivores, and water purification accomplished by wetlands. We also lose intricate ecological networks involving animals, plants and microorganisms - leading to less resilient ecosystems and loss of pools of genetic information that may prove vital to species' survival in a rapidly changing global environment. The overall scope of population losses makes clear that we cannot wait to address biodiversity loss. The authors of the study have called for curbs on the basic drivers of extinction - human overpopulation and overconsumption - and challenge society to move away from "the fiction that perpetual growth can occur on a finite planet." The Governments of East African countries will need to take on this challenge to curb the rampant loss of wildlife habitat and the resulting human-wildlife conflict that is affecting many species. Conflict between livestock farmers and carnivores is fuelling the poisoning that is decimating Africa's vultures. From wildlife authorities to researchers to communities on the ground, we must all work together to prevent vulture extinction across the planet while inspiring people to value them and to take positive action to ensure their survival.

Our work along with that of our partners over the last decade has unequivocally shown that vultures in Africa are rapidly declining. Poisoning is rampant across Africa and due to its indiscriminate nature, vultures and many other species of raptors and scavengers are being extirpated. Over the last few years and with a growing global alliance of vulture conservation organisations, great progress has been made in understanding vulture ecology and behaviour, increasing awareness about vultures and creating the next generation of African conservation leaders. Much more is needed if we are to save these denizens of the 
skies. Without urgent intervention, but also those we depend on, thus Africa's threatened vultures face placing our own future in jeopardy. I imminent extinction. The time for wonder if the person who played the action is now! vulture-bone flute nearly 40,000

We (humans) dominate the years ago ever envisioned this! planet, and are responsible for Surely we owe it to him .....for the causing an extinction event that sake of the vulture. threatens not just the species we like, 